Please do not remove this page

RMIT

UNIVERSITY

\title{
\#Drugsforsale: An exploration of the use of social media and encrypted messaging apps to supply and access drugs
}

Moyle, Leah; Childs, Andrew; Coomber, Ross; Barratt, Monica

https://researchrepository.rmit.edu.au/esploro/outputs/9921861200901341/filesAndLinks?institution=61RMIT_INST\&index=null

Moyle, L., Childs, A., Coomber, R., \& Barratt, M. (2019). \#Drugsforsale: An exploration of the use of social media and encrypted messaging apps to supply and access drugs. International Journal of Drug Policy, 63, 101-110. https://doi.org/10.1016/j.drugpo.2018.08.005

Document Version: Accepted Manuscript

Published Version: https://doi.org/10.1016/j.drugpo.2018.08.005

Repository homepage: https://researchrepository.rmit.edu.au

CC BY-NC-ND V4.0

(C) 2018 Published by Elsevier B.V. All rights reserved.

Downloaded On 2023/04/26 11:06:02 +1000 
PRE-PRINT VERSION OF: Moyle, L., Childs, A., Coomber, R. \& Barratt, M. (2018)

'\#Drugsforsale: An exploration of the use of social media and encrypted messaging apps to supply and access drugs', International Journal of Drug Policy,

\title{
\#Drugsforsale: An exploration of the use of social media and encrypted messaging apps to supply and access drugs.
}

\begin{abstract}
Background: The use of new technology is frequently harnessed by drug suppliers, to both increase profits and reduce risk. While a growing body of research has investigated drug sales through online pharmacies and cryptomarkets, despite growing media interest, no published research exists on how smart phone enabled social media applications ('apps') are utilised in the drug economy. This study analyses the ways such apps (e.g. Snapchat, Instagram and WhatsApp) are employed to both supply and access drugs.
\end{abstract}

Methods: Three data collection methods were employed: an international online survey of 358 drug users that had either used or considered using apps to access drugs; 'rapid' interviews $(n=20)$ with a similar population; and in-depth interviews $(n=27)$. Key issues explored were the perceived benefits and motivations for sourcing drugs through apps with specific attention paid to novel supply and purchasing practices.

Results: Apps appear to provide a convenient, quick option for connecting buyer and seller. They were often viewed as a valuable intermediary option between cryptomarkets and street dealing, providing 'secure' features and the opportunity to preview product without the requirement for technical expertise. Apps are used in a range of diverse ways, including as digital marketplaces and as encrypted messaging services for arranging transactions and advertising product. Key anxieties related to potential for exposure to law enforcement and legitimacy of substances.

Conclusion: Though 'social supply' through friends is still typically preferred and there is a degree of wariness toward app-based supply, our data indicate that apps are fast becoming a viable option for accessing drugs. Apps provide an easily accessible platform that connect buyers with commercial drug suppliers and substances that may otherwise remain elusive. Potential harms can be reduced through the provision of information which demystifies common-sense assumptions that apps are secure and that this 'visual' drug economy promotes safer purchasing practices.

Key words: drug markets, drug dealing, apps, cryptomarkets, dark net, risk taking, 
Snapchat, Instagram, cocaine and MDMA: How 'digital dealers' boast of making $£ 13 k$ a day selling drugs to kids. The Mirror (17 $7^{\text {th }}$ July, 2017).

\section{Introduction}

A range of recent media coverage has alluded to the way that social media apps such as WhatsApp, Tinder, Instagram and Snapchat are providing new, easier than ever routes to both supply and access (mostly recreational) drugs. Whilst the surface advantages of app mediated exchange using encrypted technology and social media platforms for prospective buyers to immediately connect with commercial suppliers initially suggests a 'next level' of drug supply, this research in fact suggests that transactions of this type may in many cases be a retrograde step. Historically, new communication technologies, often used to improve both safety and reach, have been taken up by the drug trade with enthusiasm (Natarajan, Clarke \& Johnson, 1995) and the use of the internet and internet-enabled smart phones have proven to be no exception to this trend (see Coomber \& Moyle, 2017). Prior to the 1990s, retail drug markets were typically more open, that is, where dealers located in specified public places ('open air markets') sold to both known and unknown customers (Harocopos \& Hough, 2005). While open air markets still exist in some places, firstly pagers and then mobile phone technologies were taken up to facilitate drug trading in private locations, without requiring participants to take the risk of encountering police in public places. These market arrangements became known as 'closed' markets (May \& Hough, 2004), or as 'loungeroom dealing', as opposed to 'street dealing' (Nicholas, 2008). New types of drug markets then arose in the 2000s, where websites were used to sell psychoactive drugs directly to consumers. Email lists (Schneider, 2003) and websites offered psychoactive pharmaceutical drugs (Littlejohn, Baldacchino, Schifano, \& Deluca, 2005), prescription medicines (Mackey \& Liang, 2011) and new or novel psychoactive substances (Hillebrand, Olszewski, \& Sedefov, 2010), many of which were 'legal' in some parts of the world. The sales of psychoactive substances through the internet retained some features of open markets, in that anyone could purchase without needing a social connection to a supplier, but also some features of closed markets, in that purchasers could remain in the comfort of their own home during the purchase. However, goods needed to be delivered by post and payment to such websites (as well as use of the websites) could be tracked by authorities. In the 2010 s, a new combination of digital technologies emerged in the form of the first 'cryptomarket', that is, an online marketplace that relies on anonymising technologies (e.g. Tor), cryptocurrencies (e.g. Bitcoin), and brings together a large number of buyers and 
sellers (Barratt, 2012). If used with care, cryptomarkets can be operated in an anonymous fashion, protecting the identity of both the buyer and the seller. Although goods still must be delivered, causing a risk to the buyer at the point of delivery, the risk is small due to the resources that enforcement agencies and postal organisations are actually able to commit to these prevention activities- especially for small amounts of drugs clearly for personal use (Martin, 2014b; Aldridge, Stevens \& Barratt, 2017).

An even more recent innovation, which is the topic of this paper - one that effectively negates the need for specific expertise (as with Tor based cryptomarkets) but also provides a level of hidden or encrypted communication (not provided by public listings on the surface net) - is the use of online social media applications or 'apps', typically used through smart phone technology, to trade and gain access to drugs. Although journalistic investigations into the use of apps for drug trading (e.g. BBC, 2017; Ferguson, 2016; Stroud, 2018) appear to be increasingly prevalent, there is currently an absence of academic research literature exploring the place of these new technologies in drug markets. This is so despite emerging evidence of increased use of benzodiazepines such as Xanax amongst British teenagers, with a number of commentators attributing this trend to its availability through the dark web, online pharmacies and apps (see Lee, 2018; Lewins, 2018). Despite there being opportunities for informed investigative reporting, many of the journalistic 'investigations' have lacked depth and indeed veered, as is common with media reporting of drug related issues (see Coomber et al., 2000; Alexandrescu, 2018), towards unsubstantiated sensationalism. In July 2017, a BBC documentary 'Kids selling drugs online' investigated how the use of popular social media apps like Snapchat and Instagram were 'revolutionising the way that young people buy and sell illegal drugs' in the UK. The documentary claimed that apps are commonly used to advertise the sale of illegal substances, providing a digital platform to post images and videos of product and providing the messaging service required to arrange a sale, either in person or through delivery. A number of melodramatic headlines and stories followed, branding apps as a 'dealers' paradise' (Gritt, 2017) where 'digital savvy young children buy and sell Class A drugs' (Lambert, 2017). Elsewhere, in the UK, US, Australia and beyond, online cultural magazines and user guides have also pointed to a trend toward app-based supply and provided some insight into some of the ways in which apps can be used. In an article entitled 'a user's guide to drug apps' the online magazine 'Hopes and Fears' review a number of applications including specific drug apps such as the US based 'Weedmaps', 'Nugg' and 'Leafly', along with generic social media apps such as Instagram and Wickr (see Lesser, 2015). Another online 
article explains how on social media sites like Snapchat, Instagram and Facebook 'hash tagging' - a user generated label that enables the identification of content on a particular topic - and the use of 'Emoji's' - small digital images or icons used to express an idea or emotion provide the gateway to the advertisement of the sales of a range of substances: a diamond or snowflake for cocaine, a capsule for MDMA, and needle for heroin (Ferguson, 2016). Although many of these social media platforms provide the technology to visually advertise product, it is suggested that messenger services like 'Kik', 'Wickr' or 'WhatsApp' are also harnessed to provide vendors with end-to-end encrypted communication to work out transaction details. This messaging technology has been labelled so central to drug supply that in one recent article it is claimed that a 'significant number of darknet users are migrating over' (to Wickr), and that this app and ones like it present the 'new way of online dealing' (Nolan, 2018). With media interest in app-based drug markets increasing and a distinct academic research gap in regard to this particular form of online drug acquisition, this paper aims to provide the first empirical study to explore the particular ways in which apps are utilised to access drugs.

\section{Reasons for internet drug purchasing.}

Despite the empirical research gap characterising the app-based drug economy, extant research relating to online drug markets usefully applies to this growing market and offers some insight into possible motivations and barriers to access. In cryptomarkets, safety, quality, reliability and predictability, are often referenced as reasons drug users purchase drugs online as opposed to offline 'street' markets (Van Hout \& Bingham, 2013; Bancroft \& Reid, 2016). Situational factors such as the individual's ability to access drugs through social networks and their location can also factor as push factors towards purchasing in this way (Barratt et al., 2014). Although cryptomarket customers will have to negotiate 'delivery dilemmas' (Aldridge \& Askew, 2017), qualitative research suggests purchasers are motivated by a desire to transact anonymously, without the fear of violence many associate with face-to-face trading (Martin, 2014a; Barratt, Lenton, Maddox \& Allen, 2016; Aldridge, Stevens \& Barratt, 2017). In cryptomarkets trust is proactively promoted via market structure as well as by vendors in order to attract further trade and income (Tzanetakis, Kamphausen, Werse and Laufenberg, 2015). 'Ratings systems' (Barratt et al., 2014), synonymous with many well-known cryptomarkets, provide users with an important centrally regulated review system which reduces the uncertainty commonly associated with illicit transactions and promotes confidence around drug quality (Bakken, Moeller \& Sandberg, 2017; Martin, 2014a; Aldridge \& Askew, 2017). 
In addition to trust and security, the availability, convenience and immediacy of online drug markets provides another important motivation for customers. Recent research spanning acquisition of illicit lifestyle drugs via the surface web suggest the potential to access drugs unavailable in the Netherlands and convenience provide some of the most important motivations for purchasing online (Koenraadt \& van de Ven, 2017). Such themes are also noted in cryptomarkets where wider availability and range increased frequency and use of new types of drugs (Bancroft and Reid, 2016), particularly during the 'honeymoon' period of cryptomarket access (Barratt et al., 2016:5). These findings therefore demonstrate that motivations for purchasing drugs through digital technologies are not dissimilar to the motivations described for accessing e-commerce more generally (Barratt et al., 2014). Convenience, quality and variety are typically important aspects of e-commerce when applied to legal goods as well, including entertainment and clothing (Szymanski \& Hise, 2000).

\section{Anxieties and barriers to online drug purchasing}

While there are clear benefits associated with purchasing drugs online, there are of course certain barriers to utilising surface web and cryptomarkets to access drugs. Firstly, participation in cryptomarkets - and to some extent surface web purchases - requires a computer (or equivalent device) and certain level of technical competence (Barratt \& Aldridge, 2016). The hidden nature of 'Silk Road' and other cryptomarkets limits access to its members by outsiders (van Hout and Bingham, 2013) and access to the darknet is therefore dependent on possessing a special anonymising browser, a marketplace URL and cryptocurrency (Barratt and Aldridge, 2017). If access can be negotiated, then users of cryptomarkets can face other issues. Though there has been an absence of research in this area, one study suggests that anxieties most likely to be mentioned in relation to cryptomarket purchasing include loss of money due to cryptocurrency volatility, customs seizure of product, loss of money due to market seizure/scam/theft, paying for but not receiving the product, and waiting too long to receive the product (Barratt, Ferris, \& Winstock, 2016). Though cryptomarkets sophisticated anonymising technologies are now commonly understood to 'pervade worldwide prohibitive controls' (Aldridge, Stevens \& Barratt, 2017: 1), it is suggested that 'digital traces' (see Décary-Hétu \& Aldridge, 2015) can provide opportunities for law enforcement to arrest and prosecute vendors. Cryptomarket customers are less likely to be apprehended in this way, and instead offline activities such as receiving deliveries that are more likely to render them vulnerable to prosecution (Aldridge \& Askew, 2017). Many drug users will choose not to 
purchase from cryptomarkets, and for this group one study suggests that the most common rationale offered is having 'adequate access to drugs through my own networks' followed by 'fear of being caught by police/customs if drugs are sent to my own address' (Barratt et al., 2014;). Many of these issues are specific to cryptomarkets and their structures, and to the problem of not meeting in person to exchange money for drugs. In the context of app-based dealing, which uses technology to match drug buyers and drug traders but still typically results in a physical meeting, many of these concerns are unlikely to arise but help us to understand some of the comparative appeal of app mediated access. With app-based markets situated somewhere in-between cryptomarkets and street-level drug markets, this paper describes the previously unexplored motivations, as well as the particular risks and anxieties attributed to purchasing drugs through mobile phone applications.

\section{Method}

This research is based upon data obtained from three different methodologies, an international online survey, rapid face to face 'in-situ' interviews (Measham \& Moore, 2009) and in-depth interviews, all conducted in the latter half of 2017. The online survey utilised a purposive sampling strategy to recruit prospective respondents through a combination of online advertising methods. The survey was advertised through the subreddit $r / \operatorname{Drugs}^{1}$ and placed as a moderator announcement where it remained for a period of one month with 358 responses from those who met the inclusion criteria for the study ('having sourced or had considered sourcing through a mobile phone app') included for analysis. The focus of the online survey was to gain quantitative baseline data on the demographics of app users, the apps they used and the drugs they purchased, the frequencies in which apps were used and the perceived benefits and risks of using them. Intentionally recruiting respondents who had considered but had not yet used apps also provided the opportunity to collect important data relating to the barriers and anxieties associated with using apps to access drugs. This survey was followed up with face-to-face 'rapid' interviews undertaken in Brisbane (Australia) with a further 20 individuals who fitted the inclusion criteria. The methodological approach was based upon Measham and Moore's (2009) 'in-situ' interviews or 'sweep surveys' where interviews exploring polydrug use were undertaken in local leisure scenes (p.446). Respondents were approached outside bars and nightclubs in Fortitude Valley, Brisbane, and were provided with 
details regarding anonymity and informed consent. Given the absence of academic research that explores the use of apps for drug supply, this approach provided a useful pilot study for the in-depth interviews that followed. Respondents undertaking in-depth interviews were recruited via snowball sampling through a privileged access interviewer (see Taylor \& Kierney, 2005). Due to the sensitive nature of the data and the sample being located almost exclusively in the UK, respondents elected to complete the interviews remotely rather than undertake Skype interviews. In total, 27 interviews were collected; the vast majority of the sample were students (age range 18-27), and there was an even gender split (14 identifying as men, 12 as women and 1 as non-binary). In regard to the most prevalent apps used, over half of these interviewees had used WhatsApp $(59 \% / \mathrm{n}=16)$, followed by Snapchat $(48 \% / \mathrm{n}=13)$, Facebook $(44 \% / \mathrm{n}=12)$, and Instagram $(15 \% / \mathrm{n}=4)$. Respondents were provided with a $£ 20$ reciprocal contribution as acknowledgement of their time (Ritter, Fry \& Swan, 2003). Survey data was processed via SPSS and qualitative data was coded deductively around emergent themes such as 'dealer spam', 'confidence', 'security', 'visual appeal', 'dealer preference', etc., with the resulting thematic analysis presented below. The study gained ethical approval from xxxxxx University Ethics Committee and all interview quotes have been provided with pseudonyms.

\section{Findings}

Demographic profile and patterns in app use.

In order to understand the motivations and barriers and anxieties to accessing drugs through apps our research strategy aimed to recruit both 'app users' (people who use apps to access drugs) and those who had considered using an app. The online international survey consisted of 358 respondents: 318 identifying as men, 36 as women, and four as non-binary. Overall, 288 individuals identified as app users, and a further 70 as having seriously considered using apps to purchase drugs. Age spanned from 18 to 60 and the modal value was 18 years old. Almost half of the sample indicated that that they were from the USA $(42.3 \% / \mathrm{n}=152)$ with strong representation also from Australia $(20.6 \% / \mathrm{n}=74)$, followed by Canada $(5.8 \% / \mathrm{n}=21)$ and the UK $(4.7 \% / \mathrm{n}=17)$. A majority of the participants indicated that they were from a European/Caucasian background (86.1\%); many were students (64.8\%), and over half resided with a family member (64.1\%). Highlighting app use as a relatively new phenomenon, just under half (44.3\%) of the sample indicated that they had first used apps to access drugs within the last year, followed by just under a quarter of the sample $(23.3 \%)$ indicating this to be within the last two years. A wide range of apps were reported as being used to access drugs (see Table 
1) with social media platforms Snapchat and Instagram presenting the most commonly used apps, but high representation of instant messaging apps such as Wickr, Kik, WhatsApp and Facebook Messenger. Just over half of the survey population (64.5\%) had used apps to purchase cannabis, followed by LSD (7.9\%) and MDMA (6.5\%) (see Table 2).

[Insert Tables $1 \& 2$ about here]

In regard to ways in which apps were used, differences in the preferences of apps were found, with more Australian respondents preferring to use Wickr than any other country, but more respondents from the UK electing to use WhatsApp as an encrypted messaging service than other nations. In regard to the locations in which apps were used to access drugs, despite the potential for apps' 'location services' to connect customers and suppliers in non-local geographies, interestingly, those who had used an app to access drugs were instead far more likely to use the app from their hometown (92.7\%). With regards the frequency in which apps were used by our survey sample, respondents were far more likely to have used apps on multiple occasions. Over half of those surveyed reported using apps 10 or more times $(58.5 \%)$, compared to $8.8 \%$ of respondents who had only used apps once. Future intentions with regard to apps also revealed a willingness to engage in app-based markets with over three quarters of the survey sample (84.3\%) indicating that they plan to use an app to access drugs in the future. This proclivity to continue using apps was also conveyed in interviews, with respondents describing the convenience, visual appeal and perceived security features as key benefits associated with their use (see below).

\section{Immediacy and convenience}

The most commonly reported advantage of using an app to source drugs was that it was 'more convenient to organise a transaction' (78.8\%). This theme was also prominent in interview data where a number of respondents keenly extolled the sheer ease in which they could access a virtual platform and broker a deal without the need to hassle friends, seek out a street dealer, or use what they considered as the complex technology associated with cryptomarkets (see van Hout and Bingham, 2013). Lucy (21, Cardiff) reported 'messing around with street dealers, the dark web and friends for years' as a means of accessing drugs and referred to her first time using Snapchat to buy cannabis as an 'epiphany'. Describing their initiation into purchasing drugs through Instagram, Alex (27, Plymouth) comes to a similar conclusion: 
I felt like I'd woken up in the $21^{\text {st }}$ century and that everyone around me was idiots. It was safe, easier and twice as quick as trying to nail down someone on the end of a line. The drugs turned up with the guy and I paid him and they were amazing. I never looked back.

Alex (27) Plymouth

For many of the respondents interviewed, substituting previous supply methods and drawing upon apps to access drugs was described as an 'organic' process (Olly, 18, Birmingham) that was likened to 'moving... with the modern world' (Ethan, 21, London). Adolescents rely upon social media as a core component of their social lives (Yang \& Brown, 2016) in order to build new peer affiliations, manage existing relationships and stay informed about social activities within their network (Lampe, Ellison, \& Steinfield, 2006). Although social supply clearly still predominates as a form of access for many groups and was identified as preferred supply method by the international survey sample (see also Barratt et al., 2014; Coomber \& Moyle, 2014; Barratt et al., 2016), for those without reliable social networks, it simply made sense to employ these new social media platforms - many of which respondents were already harnessing for many of their everyday social interactions:

It just seemed like a simple, modern way to buy things. I'd gotten pretty sick of the darknet because I never really got it, so had to always have a friend on hand to help me out. With apps its super simple, I get it and in no time I've managed to connect with strangers who I would've never been able to access before. Plenty of dealers in this area exist solely on Snapchat, so without it I would've kept relying on people approaching me in the street or randomly bumping into people in clubs.

\section{Zach (22) London}

Accompanying convenience, 'the speed at which drugs can be obtained' was found to be the second most commonly reported advantage to using apps (58.6\%). The immediacy of apps, hand-held, with familiar interfaces - mostly previously downloaded onto users' smart phones - provided swift, straightforward access to substances with minimal tuition required. Many previous users of cryptomarkets compared this benefit with some of the key disadvantages of cryptomarkets - the need for technical expertise and waiting for packages to be delivered. As 
one respondent concluded, the mainstay of apps is their ability to 'combine the best features of the dark web with the best of old style street dealing in a secure and easy to use package' (Danny, 23, London). Apps therefore seemed to offer an attractive 'intermediary' purchasing option that was easily available and operable, and could quickly connect buyer with seller.

\section{Range of Substances}

In addition to the convenience and speed of being able to access suppliers and order drugs directly from a virtual marketplace, interview respondents also highlighted the range of substances available as a benefit of using apps. Cryptomarket research has highlighted the potential from these 'eBay-style' online markets to connect drug users with a wider variety of substances (Barratt et al., 2014; Barratt et al., 2016; Bancroft \& Reid, 2016). Survey data indicated similar themes in app markets, with buyers purchasing substances falling outside of some of the more popular recreational repertoires, such as Mushrooms, LSD, and prescription stimulants/benzodiazepines (see table 2). In qualitative interview data, Tim (23, London) was not alone in suggesting that access to a wider variety of substances was one of 'the best feature of apps' as 'it is very rare to find a dealer out and about who carries psychedelics in this country'. Moreover, in addition to increased access to psychedelic substances, elsewhere, other respondents described how apps provided them with access to substances they were previously unable to source:

I couldn't get hold of oxy or codeine any other way because I didn't know anyone selling them so the first times I had both I brought them through apps.

\section{Jess (23) Coventry}

I hadn't ever used study drugs before I started buying them over Snapchat because I had never met anyone who carried them. One of the best features of apps is the chains it brings you into contact with, dealers often advertise other dealers and will give you their username if they know you want something they don't have.

Zach (22) London

It should be noted that these qualitative findings (primarily a UK demographic) are at odds with the international survey where a third of app using respondents reported that a 
disadvantage of apps was that it was 'hard to find the drug I am after' (34.7\%). Given that almost a quarter of app users also reported the 'wide range of drugs available' (23.4\%) as a benefit of using apps, this may be in part due to the characteristics of the international survey sample, all active forum members who might be understood as a more experimental and/or seasoned group of users with more specific preferences in regard to the strain, strength or brand of substance required. It may also be a reflection of the different contexts in which apps are being used, with the UK app market perhaps more responsive to demand for psychedelics and prescription drugs (see Lee, 2018; Lewins, 2018). Further research focusing on availability and range is required to explore these nuances, both at international and national levels.

\section{The ubiquity and 'security' of encrypted social media apps}

The use of encrypted messaging services utilised to organise supply transactions constituted one of the most popular ways in which apps were used to access drugs. Kik, Wickr and WhatsApp - apps which function primarily as instant messengers, but with added social networking features - were found to be the most prevalent apps used by survey respondents (see table 1). Many of the respondents remarked that the use of WhatsApp as a messaging service to enable communication was not understood as a 'real app' per se and was so ubiquitous that it was now considered 'a natural extension of texting' (Sam, 21, London). WhatsApp is now estimated to be used by around 1 billion people (Naughton, 2016) and its prevalence as a mobile application that can facilitate supply appears related to its general popularity as a messaging service supporting group forums and instant messaging that 'everyone uses' (Lizzy, 32, London). In addition to its popularity, it also offers the added benefit of end-to-end encryption. Though encryption was the most commonly cited security feature associated with apps, the capacity of other apps such as Snapchat and Wickr to provide transient, ephemeral messaging, through auto-destruction or 'burn on read' settings was also suggested to provide some app users further assurance of the protection of their digital trace (Décary-Hétu \& Aldridge, 2015). These qualities were highlighted in a number of interviews and appear to have traction in online communities where users make similar contrasts between the insecurity of text messages and phone calls with the safety of Snapchat, which users reason 'does not store a database of users' snaps' (still photos, videos and text) (see Reddit, 2017). Survey and interview data suggest these features not only attracted customers, but were also found to be appealing to some commercial suppliers who advertise product on Snapchat but require buyers to 'hash out the deal on WhatsApp' (Ethan (21) London). Supporting the claims 
in recent media reporting (Nolan, 2018), similar themes were identified in Australia where it was suggested that many commercial suppliers also insisted that orders were placed through Wickr, rather than traditional 'unsecure' methods. Therefore, in the same way that the advent of mobile phone technology in the 1990s offered an inexpensive, convenient form of communication that was more secure than pagers and public phones (Natarajan et al., 1995), social media platforms appear to be increasingly harnessed by sellers of illegal substances offering a digital platform that does not require specialist knowledge (van Hout \& Bingham, 2013), and offers some well-known security features that could better protect them from detection and prosecution.

Visual dealing practices and 'seeing' quality.

Alongside convenience and accessibility, data suggests another of apps' key advantages related to the notion that images and videos provided an opportunity to assess quality and safety. As well as harnessing the security features of apps, respondents widely noted the propensity for sellers to draw upon social media technology in novel ways in order to facilitate sales. Known as 'dealer spam' by many app users, practices included 'following' users with the aim to get potential customers to notice them and follow them back; sending group messages (or 'spam') to customers advertising deals and stock; and posting videos, 'stories' (a way of sharing photos and videos with followers) and a range of different images of the advertised product to followers. In some circumstances, Snapchat dealers would, for example, 'send out several messages a day' to say what they have 'and any special offers' (Zach, 22, London), or 'prove' the quality and legitimacy of their product through posting videos of 'themselves smoking or hanging with their stashes, or with their mates cruising on deliveries' (Lucy, 19 Cardiff). Practices such as these appeared to hold much appeal for many app users who contrasted the perceived risks associated with purchasing street drugs from an unknown dealer to the visual app-based drug economy. Several respondents explained that pictures of pills, white powders and prescription medicines were uploaded to advertise substances, in many cases providing 'valuable' and 'important' evidence that the substance was legitimate:

The first time I bought coke it was through an app and I thought it was a better idea to buy it that way because I could look to see if it seemed cut with anything which is really for common for coke you buy on the street around here 
Olly (18) Birmingham

The first time I bought Xanax it was through Snapchat because I could watch the dealer opening sealed packets on his story before he sold them and I therefore felt safe consuming them...I would never buy anything I hadn't tried before from some guy on a street corner or anything at all really unless I was desperate

\section{Lucy (19) Cardiff.}

As Bancroft and Reid (2016) suggest, drug users often make judgements of drug quality based on colour, texture, smell and structure, and in offline 'street' drug markets these judgements are often unreliable with limited opportunities for comparison and verification (Evrard et al., 2010). Again, highlighting the 'visual' nature of apps, a notable number of app using respondents claimed to be able to use 'stories', photos and videos to assess quality and claimed they could 'see' that a drug was unadulterated, safe and of a reasonable quality. This is not an unusual assumption in drug using populations, where a cursory examination of drug forums posts provide 'tips' for spotting good quality cocaine (see Bluelight Forum, 2013), and in PIED using populations, with empirical research suggesting, for example, that the quality of drug packaging (including vials and steroid boxes) convinced some gym users of the 'authenticity' of counterfeit anabolic steroids (see Coomber et al., 2014). Unlike cryptomarkets, which have the benefit of vendor rating systems that offer detailed comments regarding the perceived potency (Martin, 2014a), the ability to preview product provided illusionary reassurance that was perceived as unavailable in offline markets. Though not a rating system per se, a small number of respondents did reason that for Instagram users, 'likes' and comments on a single account functioned like 'Amazon reviews' (Olly 18, London) and could provide a sense of security regarding the reliability of a particular seller. In this respect and overall, as one interviewee suggested, one of the greatest perceived benefits associated with purchasing drugs through apps was the so-called 'transparency' of transactions. In regard to the level of drug information available, apps therefore seemed for many to offer 'far less than the dark web, [but] far more than the streets' (Danny, 23, London).

\section{Drug quality and personal safety}


Though a subset of those interviewed conveyed a level of confidence in their capacity to draw upon the features of certain apps to discern quality and safety, international survey respondents expressed a greater amount of concern in regard to the quality of the product they were purchasing. When questioned about their key anxieties in using apps to access drugs, the survey sample were found to be most worried about 'receiving poor quality or fake drugs' and 'receiving a substance that was the incorrect weight'. These themes also emerged in some interviews; below, Emma recalls her concerns:

You have no idea if a teenage kid is just trying to sell you rubbish (or) cut substances... (and the) main issue (with apps) is the lack of trust in the dealer as there are so many online, social media dealers.

Emma (21) Bristol

Zach (22, London) had also experienced some of these issues, stating: 'I've definitely bought bad coke before that was cut with something, Mandy (MDMA) too', and he later claimed that the adulteration of cocaine resulted in a friend having a 'fit'. It should be noted that for app users reliant on messaging services like WhatsApp, Wickr, and even Snapchat and Instagram, some may already have an established relationship with a seller, while others might draw upon these technologies simply to facilitate social supply type arrangements, or may continue to use one seller rather than continuing to meet new app sellers. Many interviewees had however experienced collecting drugs from a stranger. In contrast to anxieties conveyed by many cryptomarket users regarding exposure to 'violent' street drug markets (Martin, 2014a; Barratt et al., 2016) the online survey indicated that less than a quarter of app using respondents (23.4\%) considered sourcing drugs from an unknown dealer as 'dangerous'. Many interviewees described feeling unconcerned about this aspect of the transaction, and in Brisbane, one young woman admitted that she had not even considered these risks prior to meeting up with a seller unaccompanied. In contrast, those who had only considered purchasing drugs from a app seller were significantly more anxious, with $68.3 \%$ indicating this to be an issue. Though a small number of respondents employed strategies such as always taking someone with them (Millie, 23, London), on the whole, app users had well-rehearsed narratives that justified their continued confidence in purchasing substances from unknown suppliers, with a number asserting that it is 'bad for business' for dealers 'to be bad at business'. 


\section{Law enforcement and detection.}

Respondents who had considered using an app were found to be most worried about 'law enforcement becoming aware of the transaction' and reported 'a potential encounter with law enforcement' as the most common rationale for choosing not to use apps (65.2\%). The digital ‘trace' (Décary-Hétu \& Aldridge, 2015) associated with online interactions between user and seller was deemed the most problematic aspect of using apps to purchase drugs and it was this 'trail' (Olly 18, London) that was perceived as having the potential to expose users to undercover officers, or as providing sufficient evidence of drug possession or supply offences:

I have worries about the input of personal information, directly contacting a dealer and meeting them is not the issue. The issue lies with the process before you actually get hold of the drug itself. The planning, using personal information and having to actually go out of my way for it is something that is not attractive to me.

Sophie (23) Slough

Many of those who had dabbled with app use or had only considered using apps to purchase drugs typically spent less time researching the security of apps and as a result they admitted feeling uncertain of the extent to which personal data could be tracked by law enforcement. In Brisbane, for example, a notable number of respondents were unclear of the security of Facebook Messenger. Though a small number of respondents claimed the service was encrypted and 'not monitored by the Australian Government' (LM, 03 Brisbane), others described feeling 'uneasy' or 'nervous' arranging deals through this app, stressing that they couldn't be sure they were not being monitored. This lack of knowledge led many 'would be' or infrequent app users to conclude that it just 'wasn't worth the risk' (LM, 05, Brisbane). In contrast, more experienced app users (those who had used an app over 10 times) conveyed greater confidence in the security of apps, rating risk as lower than those who had only gained access on one occasion. In her research on young people's engagement with online drug discussion, Barratt (2011) notes the tendency for young people to believe they are unlikely to be targeted when undertaking supply transactions. In the context of app-based supply this logic was echoed and further compounded by some app users through reference to international news stories relating to app data security: 
I realised rather rapidly that Snapchat was totally secure, as was WhatsApp. Law enforcement agencies cannot [access] any data transmitted over these apps as was recently proven by several high-profile cases.

Mark (23) London

Despite the majority of users being unable to guarantee that they could not be targeted by law enforcement, app technologies seemed to promote 'feelings' of security, often through the assumption that law enforcement would 'have a hard time penetrating apps' (male, 22, Belgium) and reasoning that the likelihood they would be 'personally targeted by law enforcement' (Vicky, 20, Bristol) was very low. This logic and the additional safeguards provided by apps therefore seemed to provide enough protection and evidence to persuade many app users that occasional purchasing was safe and would go undetected.

\section{Discussion}

The diversity of app use

In the past year, use of social media applications to purchase drugs has transitioned from a little-known supply practice sitting under the radar of many drugs field researchers, to a headline national news story. Though the mainstream media have portrayed the prevalence and risks of app use in a typically reductionist and sensationalist fashion (Coomber, 2000) and while over half of our survey sample suggested they would rather purchase drugs through social supply, data here does provide evidence to suggest that apps ranging from encrypted messaging services to social media platforms are fast becoming a viable option for accessing drugs. Findings suggest that apps were utilised in a diverse range of ways including as a secure messaging service to set up deals with established social suppliers and friends; as a digital marketplace where commercial dealers could advertise their product and attract new buyers through the use of novel technology; or as a preferred communication method between commercial dealers and their regular customers. In line with some cryptomarket (Barratt et al., 2016; Barratt et al., 2014) and surface web research (Kooenraadt \& van de Ven, 2017), data indicated that convenience and speed at which apps can connect a purchaser and a seller was important attraction for app users. With many young people now 'growing up digital' (Children's Commissioner, 2017) and social media penetrating so many different facets of our social lives (Yang \& Brown, 2016), it is perhaps unsurprising that these familiar and popular 
technologies have also been harnessed to provide accessible, handheld access to digital market places and more secure communication methods for buyer and seller alike. For some, the appeal of utilising apps to purchase drugs relates to its perceived status as an intermediary market that lies in-between cryptomarkets and street-level drug markets, where certain technologies are felt to increase trust and offer increased anonymity and security without the requirement of technical competence. For others, use of apps was considered a natural progression of traditional methods such as texting, and graduation into this supply method was simply a case of moving with the times or with their friends/suppliers' preferred communication arrangement.

\section{Misinformation and false-security}

Despite many of our respondents describing anxieties about many aspects of app-based purchasing, particularly around the quality of the drugs purchased and the legitimacy of sellers, this research did nonetheless engage with a significant number of more involved drug users who conveyed a certain level of assurance around their anonymity and safety. Interestingly, for app users, encounters with law enforcement and the consequent digital footprint or trail (Décary-Hétu \& Aldridge, 2015) linked to their transaction was not deemed as the most worrying aspect of using apps to purchase drugs. Although users of apps such as WhatsApp and Wickr can, for the moment, perhaps afford to be confident of the well-publicised capacity for end-to-end encryption (Naughton, 2016), these qualities were often mistakenly ascribed to other apps such as Snapchat and Facebook Messenger. However, message ephemerality does not always equate to security and there are many third-party apps that, for example, target Snapchat's notification system (Varmazis, 2016). In the US, unopened 'Snaps' wait in limbo on servers until they are opened. In that time, if authorities have a search warrant, the Electronic Communications Privacy Act legislates that the company has to hand over the unopened Snaps left on their servers (Estes, 2013). Elsewhere, the future of encrypted security has also been called into question; in the UK, there have been repeated calls for police and intelligence services to be given access to encrypted messages on services such as WhatsApp (Hern, 2018) and the Australian Government have also pushed for social media and messaging companies to engage in cooperation and 'collaboration' with police investigations (Butler, 2017). Many caveats to security features can be explored, but the key point is that many app users are misinformed, or make erroneous assumptions regarding the protections they offer. The provision of education relating to the security risks of using apps is therefore essential. 


\section{App-based risks and harms}

In addition to risks relating to app users' digital footprint and security, there are a number of other risks, specific to these technologies, that exist in the app-based drug economy. Unlike cryptomarkets, there is no robust, reliable method for buyer or seller to establish a positive reputation, and this is further compounded due to this environment representing a market place with little incentive for suppliers to transact honestly. For some, the ability to be able to see photos and videos of product provided some assurance that the seller was legitimate and that the substance was safe. However, wider pharmacological research has long shown that the quality and safety of substances can only be measured through forensic testing and is not accessible through taste, smell or sight (see Cohen \& Sas, 1994; Coomber et al., 2014). Considering apps like Snapchat are deemed attractive due in part to their capacity for posting and sharing visual content, the belief that you can see and discern quality and safety of a particular substance is especially problematic. In addition to their technological features, apps such as Instagram and Snapchat have also changed the drug supply landscape in other meaningful ways, providing a platform to a market that could be easily accessed by customers, and that with only a small amount of research, have the potential to provide drug users with a means of connecting directly with commercial drug suppliers and substances that may otherwise remain elusive. Cryptomarkets do of course also provide access to a wider market space and diversity of substances (Barratt et al., 2016). But with around one third of respondents reporting previous purchases through surface net and cryptomarkets, and many interview respondents suggesting that their complexity can prohibit access, apps once again seem to offer an intermediary option for those without the technical expertise (van Hout \& Bingham, 2013) to access cryptomarkets. Given that most young people receive drugs from friends and acquaintances through social supply arrangements where they are largely protected from the wider drugs market (Coomber \& Turnbull, 2007), they are less likely to have access or be exposed a wider variety of substances beyond their normative repertoires. With data suggesting that a younger demographic of drug users $(m=19.74)$ have used or have considered using apps to access drugs, the potential for apps to trigger what Aldridge et al. (2017) have termed a 'supply gateway effect' requires further investigation.

\section{Conclusion}


Though the media has cast social media apps as a 'dealers' paradise' (Gritt, 2017) and drug markets as undergoing a 'digital revolution' (BBC, 2017) in how they operate, this research suggests that in reality the picture is far more complex. At the time of writing, this research provides the first academic investigation into the use of mobile phone applications in drug markets. Our findings suggest that despite the growing media hype surrounding app-based drug supply, social supply remains the preferred access method for the majority of drug users, and that anxieties around data security and risk of encounters with law enforcement prohibit many would-be users from relying on apps as a method for access. Due to the lack of research in this area and the subsequent explorative, international design of the research, findings are based upon a combination of behaviours ranging from using apps purely as a messaging service, to more involved practices such as harnessing them as a digital market place in which substances were sought out and deals made. As such, findings cannot be generalised due to both the diversity of practices and motivations exhibited, and the differing contexts in which these behaviours were undertaken. But despite these limitations, we hope to have provided some preliminary data that situates the diverse ways in which apps are harnessed to facilitate supply, and provided some preliminary analysis of new trends and potential harms that are particular to app-based drug supply. Due to the ubiquity of social media apps, their perceived convenience, and the factors outlined throughout, it seems likely that their use will continue to grow, particularly among youth populations. While there have been calls for social media giants to take concerted efforts to crackdown on illicit content (see Borromeo, 2016), it is also important that harm reduction advice is channelled toward app users. Educating young people on the possible risks of purchasing unknown substances from strangers in the digital marketplace is clearly both critical and urgent. With the survey data indicating that there exist specific anxieties around using apps, as app-based markets continue to grow, demystifying the common-sense assumptions that apps are secure and that this 'visual' drug economy promotes safer purchasing practices may also serve to promote harm reduction and behaviour change in prospective users. 


\section{References}

Aldridge, J., Stevens, A., \& Barratt, M. J. (2017). Will growth in cryptomarket drug buying increase the harms of illicit drugs?. Addiction. 10.1111/add. 13899

Aldridge, J., \& Askew, R. (2017). Delivery dilemmas: How drug cryptomarket users identify and seek to reduce their risk of detection by law enforcement. International Journal of Drug Policy, 41, 101-109.

Alexandrescu, L. (2017). 'Ethnobotanicals' and 'Spice zombies': new psychoactive substances in the mainstream media. Drugs: Education, Prevention and Policy, 1-9. 
Barratt, M. J. (2011). Discussing illicit drugs in public internet forums: Visibility, stigma, and pseudonymity. In J. Kjeldskov \& J. Paay (Eds.), C\&T '11. Proceedings of the Fifth International Conference on Communities and Technologies, Brisbane, Australia (pp. 159168). New York, NY: ACM.

Barratt, M. J. (2012). Silk Road: eBay for drugs [letter to the editor]. Addiction, 107, 683.

Barratt, M. J., \& Aldridge, J. (2016). Everything you always wanted to know about drug cryptomarkets* (*but were afraid to ask) [Editorial]. International Journal of Drug Policy, 35, $1-6$.

Barratt, M. J., Ferris, J. A., \& Winstock, A. R. (2014). Use of Silk Road, the online drug marketplace, in the UK, Australia and the USA. Addiction, 109(5), 774-783.

Barratt, M. J., Ferris, J. A., \& Winstock, A. R. (2016). Safer scoring? Cryptomarkets, social supply and drug market violence. International Journal of Drug Policy, 35, 24-31.

Bancroft, A., \& Reid, P. S. (2016). Concepts of illicit drug quality among darknet market users: Purity, embodied experience, craft and chemical knowledge. International Journal of Drug Policy, 35, 42-49.

BBC. (2017). Teens found selling drugs on Snapchat and Instagram, BBC Three investigation finds $B B C$ Three. Retrieved from http:/www.bbc.co.uk/iplayer/episode/p0581cdx/staceydooley-investigates-kids-selling-drugs-online

Bluelight (2013) Cocaine: How do I know if its good or bad quality? Available at: http:/www.bluelight.org/vb/threads/688780-Cocaine-How-do-I-know-if-its-good-or-badquality)

Borromeo, L. (2016) Drug dealers using Instagram and Tinder to find young customers. The Guardian. Available at: https://www.theguardian.com/sustainable-business/2016/apr/07/drugdealers-instagram-tinder-young-customers

Butler, J. (2017) The Government wants to access encrypted messaging apps and social media. Huffington Post. Available at: http://www.huffingtonpost.com.au/2017/06/13/thegovernment-wants-access-to-encrypted-messaging-apps-and-soci_a_22138913/

Children's Commissioner (2017) Growing up digital. A report of the growing up digital taskforce. Available at: https:/www.childrenscommissioner.gov.uk/wpcontent/uploads/2017/06/Growing-Up-Digital-Taskforce-Report-January-2017_0.pdf

Cohen, P., \& Sas, A. (1994). Cocaine use in Amsterdam in non deviant subcultures. Addiction Research, 2(1), 71-94. 
Coomber, R. (2006) Pusher Myths: Resituating the Drug Dealer. London: Free Association Books.

Coomber, R., Pavlidis, A., Santos, G. H., Wilde, M., Schmidt, W., \& Redshaw, C. (2014). The supply of steroids and other performance and image enhancing drugs (PIEDs) in one English city: fakes, counterfeits, supplier trust, common beliefs and access. Performance Enhancement \& Health, 3(3), 135-144.

Coomber, R. and Moyle, L. (2014) Beyond drug dealing: Developing and extending the concept of 'social supply'of illicit drugs to 'minimally commercial supply'. Drugs: Education, Prevention and Policy. ;21: 157-164

Coomber, R., \& Moyle, L. (2017). The changing shape of street-level heroin and crack supply in England: Commuting, holidaying and cuckooing drug dealers across 'County lines'. The British Journal of Criminology.

Coomber, R., \& Turnbull, P. (2007). Arenas of drug transactions: adolescent cannabis transactions in England-social supply. Journal of Drug Issues, 37(4), 845-865.

Coomber, R., Morris, C. and Dunn, L. (2000) 'How the Media Do Drugs: Quality Control and the Reporting of Drug Issues in the UK Print Media', International Journal of Drug Policy, 11(3): 217-225.

Décary-Hétu, D., \& Quessy-Doré, O. (2017). Are repeat buyers in cryptomarkets loyal customers? Repeat business between dyads of cryptomarket vendors and users. American Behavioral Scientist, 61(11), 1341-1357.

Estes, AC. (2013) Snapchats been handing unopened messages over to the police. Gizmodo. Available at: https://www.gizmodo.com.au/2013/10/snapchats-been-handing-unopenedmessages-over-to-the-police/

Evrard, I., Legleye, S., \& Cadet-Taïrou, A. (2010). Composition, purity and perceived quality of street cocaine in France. International Journal of Drug Policy, 21(5), 399-406.

Ferguson, R. (2016). Inside the Digital Underground of Instagram's Weed Market. Complex.

Gritt, E (2017) GOT DRUGS LOL? The disturbing new trend of teens using EMOJIS to deal Class A drugs on Snapchat and Instagram... and we reveal what the signs mean. The Sun. Available at:

https://www.thesun.co.uk/living/4016726/teenagers-drugs-emojis-stacey-dooley-bbc-three/

Global Drug Survey (2013) What's in my cocaine? Available at: https://www.youtube.com/watch?v=wyOanzI-WFs

Harocopos, A., \& Hough, M. (2005). Drug dealing in open-air markets. New York: Center for Problem Oriented Policing, US Department of Justice. 
Hern, A (2018) May calls for tech firms to act on encrypted messaging. The Guardian. Available at: https://www.theguardian.com/technology/2018/jan/25/theresa-may-calls-techfirms-act-encrypted-messaging

Hillebrand, J., Olszewski, D., \& Sedefov, R. (2010). Legal highs on the Internet. Substance Use and Misuse, 45, 330-340.

Kindland (2016) From Silk Road to Grindr: Buying and Selling Drugs on Social Media (http://www.thekindland.com/policy/from-silk-road-to-grindr-buying-and-selling-drugs-on$\underline{138)}$

Lambert, L (2017) Revealed: How teenagers use secret emoji code to deal Class A drugs on Snapchat and Instagram as gangs target 'digital savvy' school pupils. Daily Mail. Available at: http://www.dailymail.co.uk/news/article-4694888/Teenagers-using-secret-emoji-code-dealClass-drugs.html

Lesser, A (2015) A user's guide to drug apps. Hopes and Fears. Avaliable at http://www.hopesandfears.com/hopes/now/drugs/214943-drug-apps

Lee, D (2018) Anxious teenagers buy dark web tranquilisers. The Guardian. Available at: https:/www.theguardian.com/society/2018/jan/14/xanax-anxious-teenagers-buy-dark-webtranquillisers

Littlejohn, C., Baldacchino, A., Schifano, F., \& Deluca, P. (2005). Internet pharmacies and online prescription drug sales: A cross-sectional study. Drugs: Education, Prevention and Policy, $12,75-80$.

Lewins, H (2018) How British teens got hooked on Xanax. Vice. Available at: https://www.vice.com/en_uk/article/ne4mvb/how-british-teens-got-hooked-on-xanax.

Mackey, T. K., \& Liang, B. A. (2011). The global counterfeit drug trade: patient safety and public health risks. Journal of pharmaceutical sciences, 100(11), 4571-4579.

Martin, J. (2014a). Drugs on the dark net: How cryptomarkets are transforming the global trade in illicit drugs. Palgrave Macmillan.

Martin, J. (2014b). Lost on the Silk Road: Online drug distribution and the 'cryptomarket'. Criminology \& Criminal Justice, 14(3), 351-367.

May, T., \& Hough, M. (2004). Drug markets and distribution systems. Addiction Research and Theory, 12(6), 549-563.

Measham, F., \& Moore, K. (2009). Repertoires of distinction: Exploring patterns of weekend polydrug use within local leisure scenes across the English night time economy. Criminology \& Criminal Justice, 9(4), 437-464. 
Naughton, J. (2016) Your Whatsapp secrets are safe for now but big brother is still watching you. The Guardian. Available at: https:/www.theguardian.com/commentisfree/2016/apr/10/whatsapp-encryption-billion-usersdata-security

Nolan, J. (2018) This billionaire backed app is being used to buy and sell drugs. Vice. Available at: https://www.vice.com/en_au/article/paq88n/this-billionaire-backed-app-is-being-used-tobuy-and-sell-drugs

Natarajan, M., Clarke, R. V., \& Johnson, B. D. (1995). Telephones as facilitators of drug dealing. European Journal on Criminal Policy and Research, 3(3), 137-153.

Nicholas, R. (2008). The impact of social networks and not-for-profit illicit drug dealing on illicit drug markets in Australia: A discussion paper. Hobart: National Drug Law Enforcement Research Fund.

Reddit (2013) Darknet Markets. Snapchat dealing. Available at:

https://www.reddit.com/r/DarkNetMarkets/comments/5xdniq/snapchat_dealing/

Ritter, A. J., Fry, C. L., \& Swan, A. (2003). The ethics of reimbursing injecting drug users for public health research interviews: what price are we prepared to pay?. International Journal of Drug Policy, 14(1), 1-3.

Schneider, J. L. (2003). Hiding in plain sight: An exploration of the illegal(?) activities of a drug newsgroup. Howard Journal, 42, 374-389.

Szymanski, D. M., \& Hise, R. T. (2000). E-satisfaction: an initial examination. Journal of Retailing, 76(3), 309-322.

The Mirror (2017) Snapchat, Instagram, cocaine and MDMA: How 'digital dealers' boast of making $£ 13 k$ a day selling drugs to kids. The Mirror. Available at: https://www.mirror.co.uk/news/uknews/snapchat-instagram-cocaine-mdma-how-10812890.

Tofighi, B., Perna, M., Desai, A., Grov, C., \& Lee, J. D. (2016). Craigslist as a source for heroin: a report of two cases. Journal of Substance Use, 1-4.

van Buskirk, J., Roxburgh, A., Bruno, R., Naicker, S., Lenton, S., Sutherland, R., Whittaker, E., Sindicich, N., Matthews, A., Butler, K., \& Burns, L. (2016). Characterising dark net marketplace purchasers in a sample of regular psychostimulant users. International Journal of Drug Policy, 35, 32-37.

van Hout, M. C., \& Bingham, T. (2013). 'Surfing the Silk Road': A study of users' experiences. International Journal of Drug Policy, 24, 524-529. 
Varmazis, M (2016) 3 Tips for better security and privacy on snapchat. Available at: https://nakedsecurity.sophos.com/2016/08/31/3-tips-for-better-security-and-privacy-onsnapchat/

Yang, C \& Brown, B (2016) Online self-presentation on Facebook and self-development during the college transition Journal of Youth and Adolescence, 45 (2)402-416. 